\title{
Non-Contrast-Enhancing Tumor: A New Frontier in Glioblastoma Research
}

\author{
(D) A. Lasocki and (D). Gaillard
}

\begin{abstract}
SUMMARY: There is a growing understanding of the prognostic importance of non-contrast-enhancing tumor in glioblastoma, and recent attempts at more aggressive management of this component using neurosurgical resection and radiosurgery have been shown to prolong survival. Optimizing these therapeutic strategies requires an understanding of the features that can distinguish non-contrast-enhancing tumor from other processes, in particular vasogenic edema; however, the limited and heterogeneous manner in which it has been defined in the literature limits clinical translation. This review covers pertinent literature on our growing understanding of non-contrast-enhancing tumor and focuses on key conventional MR imaging features for improving its delineation. Such features include subtle differences in the degree of FLAIR hyperintensity, gray matter involvement, and focal mass effect. Improved delineation of tumor from edema will facilitate more aggressive management of this component and potentially realize associated survival benefits.
\end{abstract}

ABBREVIATIONS: $\mathrm{CET}=$ contrast-enhancing tumor; $\mathrm{FET}=\left[{ }^{18} \mathrm{~F}\right]$-fluoroethyl-L-tyrosine; $\mathrm{GBM}=$ glioblastoma; $\mathrm{nCET}=$ non-contrast-enhancing tumor

$\mathrm{T}$ he molecular characterization of gliomas has been the focus of recent glioma research. While our growing understanding of the genetics of gliomas, now reflected in the updated World Health Organization classification, provides great hope, it is easy to forget that currently, this does not substantially affect treatment options. For example, glioblastomas (GBMs) have recently been subclassified into those with a mutation in the isocitrate dehydrogenase $(I D H)$ gene and those without a mutation (known as IDH wild-type). ${ }^{1}$ While IDH mutant GBMs have a significantly better prognosis than IDH wild-type tumors, ${ }^{1,2}$ conventional treatment for both subtypes currently remains the same. ${ }^{3}$ Unlike the treatment of many extracranial malignancies, which has been revolutionized by the development of immunotherapy ${ }^{4}$ and monoclonal antibodies against key drivers of tumorigenesis, ${ }^{5}$ progress in the treatment of diffuse gliomas has been slower and they remain largely incurable. Until new treatment

Received December 8, 2018; accepted after revision February 5, 2019

From the Department of Cancer Imaging (A.L.), Peter MacCallum Cancer Centre, Melbourne, Victoria, Australia; Sir Peter MacCallum Departments of Oncology (A.L.) and Radiology (F.G.), University of Melbourne, Parkville, Victoria, Australia; and Department of Radiology (F.G.), Royal Melbourne Hospital, Parkville, Victoria, Australia.

Paper previously presented, in part, at: Annual Meeting of the European Society of Neuroradiology, September 19-23, 2018; Rotterdam, the Netherlands.

Please address correspondence to Arian Lasocki, MD, Department of Cancer Imaging, Peter MacCallum Cancer Centre, Grattan St, Melbourne, Victoria, Australia 3000; e-mail: arian.lasocki@petermac.org

- Indicates open access to non-subscribers at www.ajnr.org

http://dx.doi.org/10.3174/ajnr.A6025 options enter clinical practice, it is, therefore, important to optimize existing therapies. This is arguably of greater importance now than ever before because with longer survival, also comes the growing prospect of living long enough to benefit from new emerging therapeutic options.

GBM is the most aggressive-and, unfortunately, most common-form of diffuse glioma. ${ }^{1}$ The treatment of GBM typically consists of maximal safe neurosurgical resection followed by adjuvant chemoradiotherapy. ${ }^{3}$ Gross macroscopic resection of the contrast-enhancing tumor (CET) component of GBMs is associated with longer survival ${ }^{6-8}$ and thus represents the neurosurgical standard of care. Despite satisfactory resection and adjuvant chemoradiotherapy, however, local recurrence of GBM is almost inevitable due to tumor cells infiltrating beyond the CET component. ${ }^{9}$ Often, at least a portion of the tumor extending beyond the contrast-enhancing margin is visible with MR imaging and is known as non-contrast-enhancing tumor (nCET), usually best visualized on T2-weighted FLAIR imaging.

The frequency with which complete or near-complete resection of the CET component can be achieved is increasing due to technologic advances, including neuronavigation techniques, fluorescence-guided surgery, and intraoperative MR imaging, which are translating into improved survival. ${ }^{10-12}$ The potential gains from improved resection of the CET component are thus plateauing, increasing the importance of residual nCET. Historically, nCET in the context of a GBM has been thought to be of a lower grade. This view is being refuted because such nCET frequently progresses faster than one would expect purely on the basis of 
imaging appearances, with even distant areas of nCET rapidly evolving to CET in patients with $I D H$ wild-type GBM. ${ }^{13}$ The high malignant potential of the nCET component is supported by our growing understanding of the genetics of gliomas, with $I D H$ wildtype grade II and III tumors typically behaving more like GBMs than their IDH mutant counterparts of equivalent grade, ${ }^{1}$ leading to the colloquial term "stealth glioblastomas." If anything, the nCET component of a GBM could be expected to be more advanced genetically than in lower grade IDH wild-type tumors because dedifferentiation has already occurred in another portion of the tumor. The nCET component is also typically highly cellular. Eidel et $\mathrm{al}^{14}$ recently showed that nCET had the highest content of viable tumor cells-higher than that present within the CET or necrotic components.

\section{Non-Contrast-Enhancing Tumor Affects Prognosis}

It is increasingly being recognized that the nCET component of a GBM affects prognosis. Jain et $\mathrm{al}^{15}$ showed that both nCET crossing the midline and elevated relative cerebral blood volume within the nCET component are associated with shorter survival. Similarly, Lasocki et $\mathrm{al}^{16}$ found that those with peripheral GBMs with substantial cortical nCET (a subset of the total nCET) have shorter survival than those with peripheral tumors without this component. These findings are supported by studies assessing the postoperative residual nCET component. Grabowski et $\mathrm{al}^{17}$ found that T2/FLAIR residual volume was a significant predictor of survival on both univariate and multivariate analysis. These results have recently been validated by a multicenter study showing that high postoperative residual nonenhancing volume conveyed a worse prognosis. ${ }^{18}$

$I D H$ wild-type GBMs are much more common than their IDH mutant counterparts ${ }^{1}$ and almost certainly accounted for most tumors in the above studies. Thus, prognostic significance can most confidently be attached to residual nCET for an $I D H$ wildtype GBM, but it is less clear for IDH mutant GBMs. The association between a greater proportion of nCET and the presence of an $I D H$ mutation was first described by Carrillo et al. ${ }^{19}$ Substantial nCET is more common in IDH mutant GBMs, though also relatively common in IDH wild-type GBMs, limiting the strength of this association. ${ }^{20}$ Specifically, IDH mutations are present in only about $5 \%$ of all glioblastomas, ${ }^{2}$ while substantial $(>33 \%)$ nCET is present in about $21 \%$ of $I D H$ wild-type glioblastomas. ${ }^{20}$ Thus, a glioblastoma with substantial nCET is nevertheless more likely to be $I D H$ wildtype than $I D H$ mutant. ${ }^{20}$ Knowledge of the $I D H$ status is, therefore, important in determining the significance of nCET. While greater residual nCET generally conveys a worse prognosis provided it is not simply related to $I D H$ mutant status, the survival benefit conferred by an $I D H$ mutation is likely to substantially outweigh the detrimental effect of greater residual nCET.

\section{The Effect of Antiangiogenic Therapy}

Antiangiogenic agents such as bevacizumab and cediranib often produce a rapid decrease in the degree of contrast enhancement as a result of reconstitution of the disrupted blood-brain barrier. This does not represent a true response, however; thus, the phenomenon is known as a pseudoresponse. ${ }^{21}$ Assessment of CET is less reliable in these patients, and monitoring nCET takes on greater importance. This is reflected in the updated Response Assessment in Neuro-Oncology criteria, ${ }^{22}$ and inclusion of T2/ FLAIR imaging in patients treated with bevacizumab has been shown to improve the prediction of survival beyond that achieved by assessment based solely on postcontrast imaging. ${ }^{23,24}$ Because T2 hyperintensity can have many contributors, assessment of nCET requires determining that the increase in $\mathrm{T} 2$ hyperintensity is attributable to tumor progression. ${ }^{24}$ Thus, knowledge of the features of nCET is critical. The morphology of nCET in patients treated with antiangiogenic agents may also be important, with Nowosielski et $\mathrm{al}^{25}$ having shown that a circumscribed pattern of progressive T2 hyperintensity in patients treated with bevacizumab is associated with shorter survival compared with a diffuse pattern.

\section{Neurosurgical Resection of Non-Contrast-Enhancing Tumor}

A growing appreciation of the importance of nCET in GBM has led some authors to suggest extending the surgical resection to the nCET component, rather than solely focusing on CET. ${ }^{15,16}$ The goal, at this stage, remains to delay progression and the development of symptomatic recurrence rather than provide a cure. A similar strategy was successfully used in grade II gliomas by Yordanova et $\mathrm{al}^{26}$ who performed "supratotal resection" in 15 cases. This was defined as extension of the resection beyond the area of signal abnormality visible on MR imaging, compared with confining the resection to the region of abnormal signal. ${ }^{26}$ This cohort had a lower rate of anaplastic transformation and a lower rate of requiring adjuvant treatment compared with a control cohort. ${ }^{26}$

Recent effort to more aggressively resect nCET in GBM has also shown additional prognostic benefit over that achieved by gross macroscopic resection of the CET component alone. Li et $\mathrm{al}^{27}$ showed that in patients in whom total resection of the CET component was achieved, resection of $\geq 53.21 \%$ of the surrounding FLAIR abnormality conveyed an additional survival benefit. These patients had a median survival of 20.7 months, compared with 15.5 months when $<53.21 \%$ of the surrounding FLAIR abnormality was resected. ${ }^{27}$ Pessina et $\mathrm{al}^{28}$ had similar results, though they examined the extent of resection differently. Patients who had undergone supratotal resection, namely those in whom the entirety of the CET component and the surrounding FLAIR hyperintensity were resected, had an impressive median survival of 29 months. ${ }^{28}$ Of note, this definition varies from that used by Yordanova et $\mathrm{al}^{26}$ because they did not aim to extend the resection beyond the area of FLAIR hyperintensity. ${ }^{28}$ In contrast, patients with gross total resection (defined as $\geq 90 \%$ ) of the CET component and variable resection of the infiltrative tumor component had a median survival of 16 months. For patients with gross total resection of the CET component, $45 \%$ resection of the infiltrative tumor component was the threshold that conveyed a survival benefit, achieving a 2-year survival rate of $54 \%$ compared with $12 \%$ when resection of the infiltrative component was less extensive. ${ }^{28}$ The thresholds identified by these authors are somewhat arbitrary, and in practice, the extent will be limited by the neurosurgeon's ability to visualize and safely resect the nCET component. Most interesting, Beiko et $\mathrm{al}^{29}$ found that greater resection 
of nCET was associated with improved prognosis only in $I D H$ mutant malignant astrocytomas (grades III and IV), but not in $I D H$ wild-type tumors of the same grades.

Although the results of these neurosurgical studies are impressive, the limited and heterogeneous manner in which the nCET component was defined in these studies raises questions. The definition of Li et $\mathrm{al}^{27}$ was simply that of the "surrounding FLAIR abnormality," and this is overly simplistic on the basis of our knowledge of gliomas. GBMs are typically associated with at least some surrounding edema; thus, it is difficult to determine how much of the nCET component was truly resected, and this will have been dependent on the relative contributions of nCET and edema to the overall area of FLAIR abnormality. While one can assume that some effort was made to target areas that were thought to represent nCET, presumably based on the MR imaging appearances, the limited description of the methods of Li et al limits translation into clinical practice. The description provided by Pessina et $\mathrm{al}^{28}$ is similarly unclear. While they do discuss the surrounding FLAIR abnormality representing infiltrative tumor, there is no indication as to how or if this was differentiated from vasogenic edema.

Similar limitations are present in the aforementioned studies assessing postoperative residual FLAIR hyperintensity. Grabowski et $\mathrm{al}^{17}$ acknowledged that a portion of the residual FLAIR hyperintensity may represent edema, both persisting after resection of the tumor (because this takes a variable time to resolve) and related to the surgery itself. The possibility of persistent edema is also relevant to the association with prognosis because Pope et $\mathrm{al}^{30}$ have shown that more pronounced edema at diagnosis is associated with worse survival. Thus, unless effort has been made to specifically distinguish nCET from edema, part of the worse prognosis related to a greater amount of residual FLAIR hyperintensity postoperatively could simply relate to a tumor that induces more edema, rather than necessarily residual nCET.

The patterns of nCET vary substantially among patients, ${ }^{31}$ though the literature on this topic is limited. These patterns themselves may have prognostic implications ${ }^{31}$ that have not been accounted for in the above studies. For example, nCET having a masslike morphology or preferentially involving the gray matter may be associated with a better prognosis than a pattern infiltrating the white matter. ${ }^{31}$ These more favorable morphologies are also generally easier to delineate, which is important if one is planning more aggressive resection. Furthermore, their typically more superficial location (compared with nCET involving the white matter) is likely to be associated with less surgical morbidity, again assisting surgical resection. There is thus the potential for selection bias in the above neurosurgical studies because more aggressive resection may have been facilitated by the nCET having a morphology that, in itself, conveyed an improved prognosis, compared with patients with a more infiltrative-and thus more difficult to resect-pattern of nCET.

Such considerations are supported by the results of Baldock et $\mathrm{al}^{32}$ who divided GBMs into "nodular" and "diffuse" based on a mathematic calculation of "relative invasiveness." This study found that nodular tumors received a significant survival benefit from gross total resection of CET over subtotal resection or biopsy, but diffuse tumors did not. While this study examined re- section of CET rather than nCET, the morphologic patterns assessed are equally relevant to nCET. Similarly, IDH mutant malignant astrocytomas (grades III and IV) have been shown to be more amenable to complete resection of CET than their IDH wild-type counterparts. ${ }^{29} \mathrm{IDH}$ status was not disclosed in the study by $\mathrm{Li}$ et $\mathrm{al}^{27}$; thus, a component of the improved prognosis attributed to more extensive resection could have related to a greater proportion of $I D H$ mutant tumors, which will in itself have conveyed a better prognosis. Nevertheless, the effect of the potential for a greater proportion of $I D H$ mutant tumors is likely to have been small, given the low frequency of $I D H$ mutations in glioblastoma, ${ }^{2}$ well-demonstrated by the cohort of Pessina et $\mathrm{al}^{28}$ (with only $3.2 \%$ of tumors being $I D H$ mutant).

Despite these potential confounders, the size of the survival benefit described is such that there is nevertheless likely to be true benefit to more aggressive resection, and this benefit is intuitive given our knowledge of the growth patterns of GBM. The same neurosurgical advances aiding resection of CET, as briefly outlined above, will also facilitate more aggressive resection of nCET. As a result, the identification and delineation of nCET are likely to become an increasingly important element of the preoperative MR imaging assessment of all diffuse gliomas, irrespective of grade.

\section{New Avenues in Radiation Oncology}

Aggressive resection of CET is not always possible, however, for example, due to the proximity to eloquent structures and the associated risks of operative morbidity. Such considerations are amplified if aiming to extend the resection to nCET because functioning brain tissue is potentially embedded with the nCET component. This feature highlights the important role of optimal adjuvant radiation therapy. Postoperative radiation therapy, according to the protocol of Stupp et al, ${ }^{33}$ has been the standard of care for GBM for many years, though tumor recurrence remains largely inevitable. This has prompted investigation into more aggressive management of the nCET component with radiation therapy, and this has also been shown to convey a survival benefit. ${ }^{34}$ Duma et $\mathrm{al}^{34}$ have described a technique of performing radiosurgery to the "leading edge" of a GBM, namely the migratory white matter pathways adjacent to and leading away from the CET component. The patients in their series had a median overall survival of 23 months, which is substantially longer than that in other comparable series. ${ }^{33,34}$ These results provide further evidence supporting aggressive management of nCET in GBMs and again highlight the importance of not only high-quality pretreatment imaging but also careful re-imaging shortly before commencing radiation therapy. Edema related to CET may have receded, aiding delineation of nCET. Volumetric FLAIR imaging is likely to be of particular value in this context.

\section{Identification of Non-Contrast-Enhancing Tumor}

To facilitate more aggressive management of nCET, there is a need to improve its accurate identification. In the preoperative setting, the main contributors to the FLAIR hyperintensity surrounding the CET component of a glioma are nCET and vasogenic edema. It is well-accepted that there is some overlap of these 2 etiologies, in particular adjacent to the CET component, but often a confident distinction of the dominant process is possible 


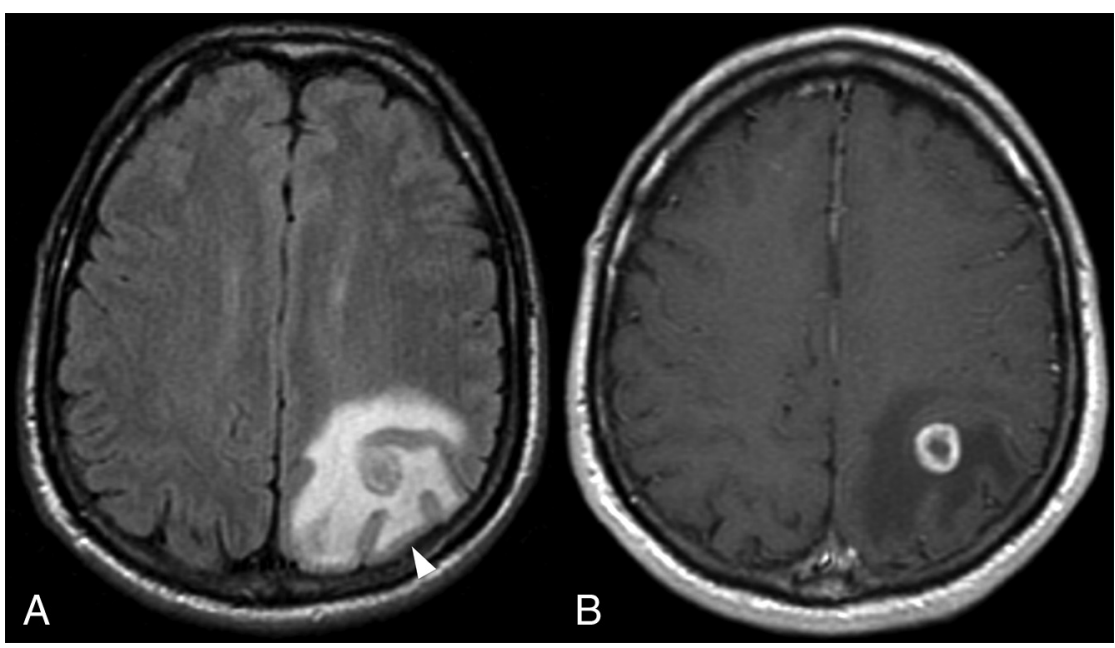

FIG 1. FLAIR imaging $(A)$ showing edema around the CET component $(B)$ sparing the cortex (arrowhead), producing the characteristic fingerlike appearance.

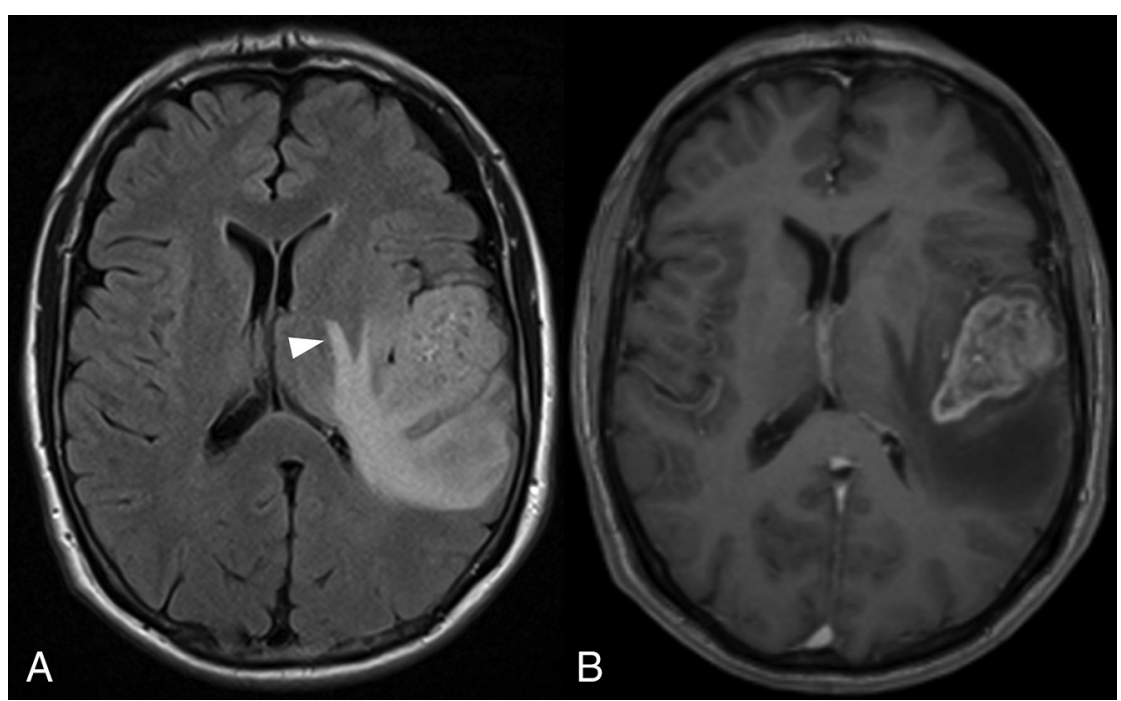

FIG 2. FLAIR imaging $(A)$ showing edema extending around the left lentiform nucleus. The CET component is shown in $B$.

for at least a portion of the signal abnormality. We aimed, therefore, to provide and illustrate criteria that can help distinguish nCET and edema. Confirming that an abnormality on MR imaging correlates with nCET histopathologically is problematic because it is frequently not resected or separately biopsied. Even a comprehensive postmortem examination is limited by difficulties with coregistration and sampling error. As a result, these imaging criteria have been developed, in part, on the basis of knowledge of the imaging appearances and evolution, but they are nevertheless well accepted as evidenced by the description of similar strategies in the widely used Visually Accessible Rembrandt Images set of MR imaging features of glioma. ${ }^{35}$ As technology improves, these principles are increasingly being validated by studies correlating imaging-guided biopsies with colocalized MR imaging metrics.

Although advanced MR imaging techniques such as MR spectroscopy and perfusion have value in determining the extent of nCET preoperatively, they are not universally available and are time-consuming and operator-dependent. These practical considerations are particularly relevant given the increasing use of intraoperative MR imaging because assessment of residual nCET intraoperatively is based on conventional sequences. Even when advanced sequences are used preoperatively, it is useful to correlate these with the appearance on conventional sequences. For example, if CBV is elevated outside the CET component, there may be correlative features on T2WI and FLAIR.

Edema has several characteristic features. Edema is typically confined to the white matter, sparing the cortical ribbon and thus producing the characteristic fingerlike appearance (Fig 1). ${ }^{30}$ Correlating with standard T2WI is useful for identifying this appearance because the cortex is usually better visualized. ${ }^{16,30}$ Similar gray matter sparing of deep gray matter nuclei is also seen, with edema extending along the internal and external capsules (Fig 2). In contrast, gliomas frequently involve gray matter, ${ }^{16,36-38}$ and such involvement can be confidently diagnosed as nCET (Figs 3 and 4). ${ }^{16}$

The white matter involvement of edema is typically relatively concentric around the enhancing lesions, other than where hindered by the relative barrier afforded by the gray matter. In contrast, eccentric extension of FLAIR hyperintensity, not accounted for by anatomic constraints, is highly suggestive of nCET. Wallerian degeneration is the main differential to consider for FLAIR hyperintensity along the course of the corticospinal tract, but this is most commonly seen in the context of a resection cavity or large necrotic tumor involving the precentral gyrus. There is also usually appreciable volume loss, aiding the distinction. Parenchymal expansion, conversely, is a useful feature to confirm nCET, particularly in the corpus callosum (Fig 4).

Another useful differentiating feature is that edema is typically associated with more marked T2 and FLAIR hyperintensity than nCET, ${ }^{30}$ often fading somewhat toward the periphery of the edema. In contrast, FLAIR hyperintensity related to nCET is usually more subtle. The relatively mild FLAIR hyperintensity of nCET is well-demonstrated in the gray matter where the distinction is simpler but can also be seen in the white matter, for example with an eccentric tongue of nCET extending beyond an area that has the typical appearance of edema. This finding has recently been supported by a study correlating radiographically localized biopsies with multiparametric MR imaging, which found that T2 FLAIR was inversely correlated with cell density. ${ }^{39}$ These results support mild FLAIR hyperintensity being a feature of nCET, while greater hyperintensity indicates that edema dominates. 


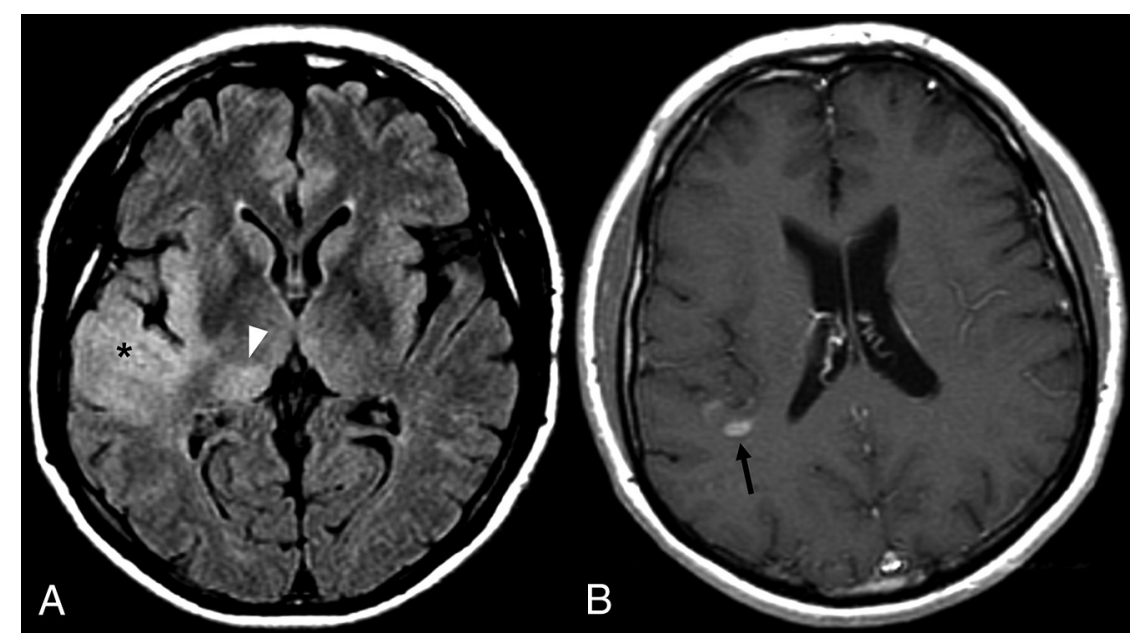

FIG 3. FLAIR imaging $(A)$ demonstrating $n C E T$ involving the anterior right temporal cortex (asterisk), insula, and thalamus (arrowhead). A narrow window width has been used to improve conspicuity. The small CET component lies further superiorly ( $B$, arrow).

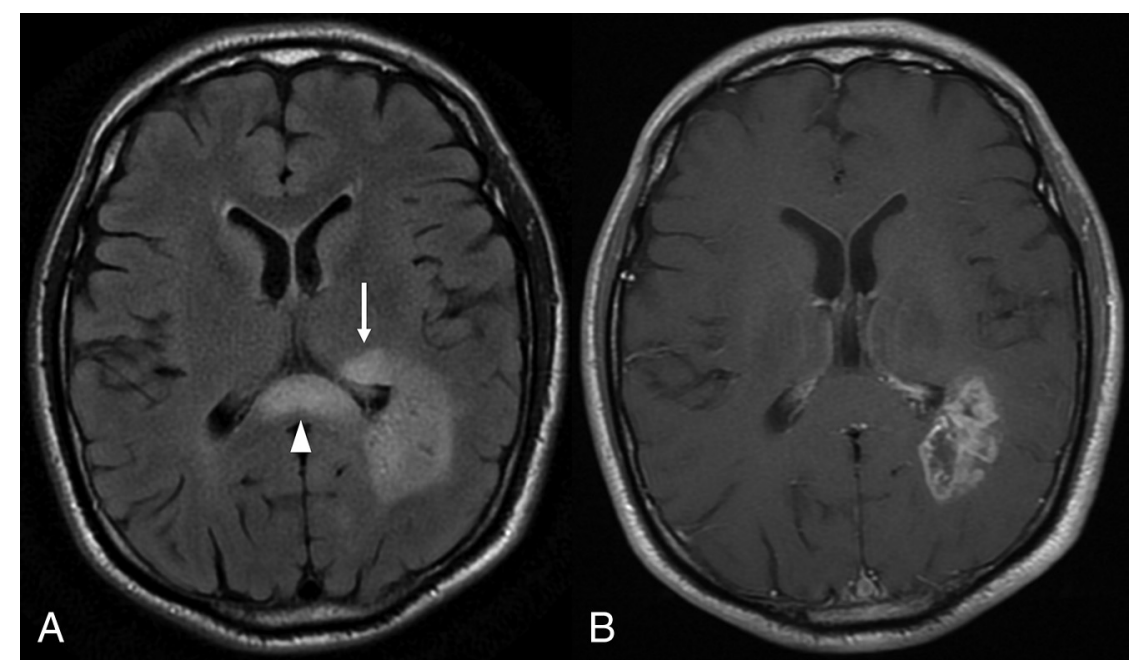

FIG 4. FLAIR imaging $(A)$ showing eccentric extension of nCET across the corpus callosum, with associated expansion (arrowhead). Rounded hyperintensity in the left thalamus (arrow) is also consistent with nCET. Note the paucity of edema in the white matter immediately adjacent to the CET component (B).

Conventional and advanced MRI features useful for differentiating between nCET and edema

\begin{tabular}{|c|c|}
\hline nCET & Edema \\
\hline \multicolumn{2}{|l|}{ Conventional MRI features } \\
\hline Gray matter involvement & Spares the gray matter \\
\hline Eccentric & $\begin{array}{l}\text { Relatively concentric around } \\
\text { enhancing lesions }\end{array}$ \\
\hline $\begin{array}{l}\text { Relatively mild FLAIR and T2 } \\
\text { hyperintensity }\end{array}$ & $\begin{array}{l}\text { More marked FLAIR and T2 } \\
\text { hyperintensity }\end{array}$ \\
\hline Focal parenchymal expansion & $\begin{array}{l}\text { More diffuse mass effect if } \\
\text { marked edema }\end{array}$ \\
\hline \multicolumn{2}{|l|}{ Advanced MRI sequences } \\
\hline Relative diffusion restriction & Facilitated diffusion \\
\hline $\begin{array}{l}\text { Choline elevation, NAA } \\
\text { depletion }\end{array}$ & Normal MRS findings \\
\hline Elevated rCBV around CET & $\begin{array}{l}\text { rCBV elevation confined } \\
\text { to CET }\end{array}$ \\
\hline
\end{tabular}

Note:- rCBV indicates relative cerebral blood volume.
A final conventional MR imaging feature useful for identifying nCET is mass effect. The edema surrounding CET may be extensive and may produce generalized mass effect, though often this is less pronounced. In contrast, the mass effect from nCET is often more focal, with parenchymal expansion and distortion rather than compression. Edema can thin the cortex and thus mimic cortical involvement, but relative expansion of the cortex, even mild, is convincing evidence of nCET. Expansion of nCET may be more rounded and mass-like, ${ }^{31}$ and this appearance is perhaps most easily identified as nCET. A white matter infiltration pattern of nCET is typically associated with less mass effect, but other features, as described above, usually allow this distinction. Multifocality, in which there is evidence of a communication between enhancing lesions, most commonly on FLAIR imaging, ${ }^{40}$ can also be used to infer intervening nCET.

Despite our best effort, we acknowledge that the above criteria do not allow the complete differentiation between nCET and edema in many patients. In particular, even when effort is made to identify areas confidently diagnosable as nCET, this will underestimate its true extent. Areas of FLAIR hyperintensity that have the typical appearance of edema will almost inevitably contain some nCET to a degree that is both variable and difficult to determine. Advanced MR imaging sequences are thus most useful in the white matter and are well-established. With the growing number of available techniques, a comprehensive review of these is beyond of the scope of this article, but the key features are discussed briefly below. Both the conventional and advanced MR imaging features for identifying nCET are summarized in the Table.

The potential use of DWI for identifying nCET is based on the correlation between ADC values and tumor cellularity. ${ }^{41-43}$ This association suggests that relative diffusion restriction (lower ADC values) is a marker of $\mathrm{nCET}$, in contrast to the facilitated diffusion occurring with edema. ${ }^{44}$ Published results have been conflicting, ${ }^{41,44-46}$ but reassuring results have been obtained with newer techniques. For example, Price et $\mathrm{al}^{47}$ have suggested value in DTI, with infiltrating tumor suggested by the presence of an increase in the isotropic component of the diffusion tensor and a marginal increase in the anisotropic component. Stadlbauer et $\mathrm{al}^{48}$ have suggested that fractional anisotropy correlates better with histopathologic parameters than mean diffusivity. Functional diffu- 
sion maps and high-b-value DWI have also been suggested as useful tools for identifying nCET. ${ }^{49,50}$

On MR perfusion imaging, nCET can be identified by relative CBV elevation outside the CET component, and again it is relative to normal parenchyma. Although relative CBV elevation may be a marker more of tumor vascularity than cellularity, ${ }^{51}$ a correlation with both microvascular density and cell density has been suggested. ${ }^{52}$ Identifying nCET based on diffusion restriction and elevated relative CBV may be particularly important because both features predict the subsequent development of enhancement. ${ }^{53,54}$ It is possible, however, that a confident diagnosis of nCET on conventional sequences also predicts transformation to a higher grade; indeed, this seems to be the case for visible cortical nCET, ${ }^{13}$ though the literature on this topic is limited.

The use of MR spectroscopy for identifying nCET is based on the presence of a "glioma trace," with choline elevation (denoting increased membrane turnover) and decreased NAA. It is not clear, however, whether such MR spectroscopy changes necessarily imply that nCET is the dominant process (above edema), a finding important when weighing the risks and benefits of more aggressive resection. Greater degrees of choline elevation and/or NAA depletion are associated with higher histologic grades of glioma $^{55,56}$; thus, it may be useful to use an MR spectroscopy threshold to predict value in resection.

In some cases, there will be overlap between features (both conventional and advanced); while in others, nCET will be identifiable by only a single MR imaging sequence or specific MR imaging feature. It is, therefore, important to use a multiparametric approach to improve both sensitivity and specificity for identifying nCET and to confirm that it is the dominant process within a given area of signal abnormality. This approach is not limited to MR imaging, and the addition of PET has the potential to provide complementary information. The most commonly used PET tracer, FDG, has limited use in the brain due to high uptake in normal brain tissue. This has, however, been overcome by the introduction of novel PET tracers, such as the amino acid tracer $\left[{ }^{18} \mathrm{~F}\right]$-fluoroethyl-L-tyrosine (FET), and FET-PET can be combined with MR imaging to improve delineation of nCET and thus aid radiation therapy planning. ${ }^{57,58}$

Computational methods are also being investigated. For example, Artzi et $\mathrm{al}^{59}$ have suggested that combining radiomic texture analysis with machine learning may improve the delineation of nCET. The authors themselves concede that histologic validation remains a limitation, though some of this concern has been overcome by $\mathrm{Hu}$ et al, ${ }^{60}$ who correlated similar techniques with image-guided biopsies and were able to identify nCET with an accuracy of $88 \%$ in both the training and validation cohorts. Nevertheless, specificity remains a consideration when identifying subtle differences not readily discernible by the human eye. Such subtle nCET would be expected to contain a lower proportion of tumor cells than areas identified by a neuroradiologist, and a neurosurgeon may hesitate to extend the resection. With time, quantification of such techniques can be expected to improve, and the combination of computational techniques with a growing armamentarium of MR imaging sequences likely represents the future of this field. It will be some time until such techniques are disseminated into routine clinical practice, however, and optimizing the use and interpretation of conventional sequences remain a priority.

\section{CONCLUSIONS}

There is a growing understanding of the prognostic importance of nCET in GBM. Extending neurosurgical resection beyond CET to the nCET component is associated with improved survival, as is more aggressive targeting of nCET with radiosurgery. Optimizing these therapeutic strategies requires an understanding of the features that can differentiate nCET from other causes of signal abnormality, in particular edema. Improved delineation of nCET from edema will facilitate more aggressive management of nCET and the associated survival benefits.

\section{REFERENCES}

1. Louis DN, Ohgaki H, Wiestler OD, et al. World Health Organization Histological Classification of Tumors of the Central Nervous System. Lyon: International Agency for Research on Cancer; 2016

2. Yan $H$, Parsons DW, Jin G, et al. IDH1 and IDH2 mutations in gliomas. N Engl J Med 2009;360:765-73 CrossRef Medline

3. Weller M, van den Bent M, Tonn JC, et al; European Association for Neuro-Oncology (EANO) Task Force on Gliomas. European Association for Neuro-Oncology (EANO) guideline on the diagnosis and treatment of adult astrocytic and oligodendroglial gliomas. Lancet Oncol 2017;18:e315-29 CrossRef Medline

4. Karachaliou N, Gonzalez-Cao M, Sosa A, et al. The combination of checkpoint immunotherapy and targeted therapy in cancer. Ann Transl Med 2017;5:388 CrossRef Medline

5. Lee YT, Tan YJ, Oon CE. Molecular targeted therapy: treating cancer with specificity. Eur J Pharmacol 2018;834:188-96 CrossRef Medline

6. Hardesty DA, Sanai N. The value of glioma extent of resection in the modern neurosurgical era. Front Neurol 2012;3:140 CrossRef Medline

7. Lacroix M, Abi-Said D, Fourney DR, et al. A multivariate analysis of 416 patients with glioblastoma multiforme: prognosis, extent of resection, and survival. J Neurosurg 2001;95:190-98 CrossRefMedline

8. Stummer W, Reulen HJ, Meinel T, et al; ALA-Glioma Study Group. Extent of resection and survival in glioblastoma multiforme: identification of and adjustment for bias. Neurosurgery 2008;62:564-76; discussion 564-76 CrossRef Medline

9. Chamberlain MC. Radiographic patterns of relapse in glioblastoma. J Neurooncol 2011;101:319-23 CrossRef Medline

10. Kubben PL, ter Meulen KJ, Schijns OE, et al. Intraoperative MRIguided resection of glioblastoma multiforme: a systematic review. Lancet Oncol 2011;12:1062-70 CrossRef Medline

11. Schulz C, Waldeck S, Mauer UM. Intraoperative image guidance in neurosurgery: development, current indications, and future trends. Radiol Res Pract 2012;2012:197364 CrossRef Medline

12. Zhao $\mathrm{S}$, Wu J, Wang $\mathrm{C}$, et al. Intraoperative fluorescence-guided resection of high-grade malignant gliomas using 5-aminolevulinic acid-induced porphyrins: a systematic review and meta-analysis of prospective studies. PLoS One 2013;8:e63682 CrossRef Medline

13. Lasocki A, Gaillard F, Tacey MA, et al. The incidence and significance of multicentric noncontrast-enhancing lesions distant from a histologically-proven glioblastoma. J Neurooncol 2016;129:471-78 CrossRef Medline

14. Eidel O, Burth S, Neumann JO, et al. Tumor infiltration in enhancing and non-enhancing parts of glioblastoma: a correlation with histopathology. PLoS One 2017;12:e0169292 CrossRef Medline

15. Jain R, Poisson LM, Gutman D, et al. Outcome prediction in patients with glioblastoma by using imaging, clinical, and genomic biomarkers: focus on the nonenhancing component of the tumor. Radiology 2014;272:484-93 CrossRef Medline

16. Lasocki A, Gaillard F, Tacey M, et al. Incidence and prognostic sig- 
nificance of non-enhancing cortical signal abnormality in glioblastoma. J Med Imaging Radiat Oncol 2016;60:66-73 CrossRef Medline

17. Grabowski MM, Recinos PF, Nowacki AS, et al. Residual tumor volume versus extent of resection: predictors of survival after surgery for glioblastoma. J Neurosurg 2014;121:1115-23 CrossRef Medline

18. Kotrotsou A, Elakkad A, Sun J, et al. Multi-center study finds postoperative residual non-enhancing component of glioblastoma as a new determinant of patient outcome. J Neurooncol 2018;139:125-33 CrossRef Medline

19. Carrillo JA, Lai A, Nghiemphu PL, et al. Relationship between tumor enhancement, edema, IDH1 mutational status, MGMT promoter methylation, and survival in glioblastoma. AJNR Am J Neuroradiol 2012;33:1349-55 CrossRef Medline

20. Lasocki A, Tsui A, Gaillard F, et al. Reliability of noncontrast-enhancing tumor as a biomarker of IDH1 mutation status in glioblastoma. J Clin Neurosci 2017;39:170-75 CrossRef Medline

21. Hygino da Cruz LC Jr, Rodriguez I, Domingues RC, et al. Pseudoprogression and pseudoresponse: imaging challenges in the assessment of posttreatment glioma. AJNR Am J Neuroradiol 2011;32: 1978-85 CrossRef Medline

22. Wen PY, Macdonald DR, Reardon DA, et al. Updated response assessment criteria for high-grade gliomas: Response Assessment in Neuro-Oncology Working Group. J Clin Oncol 2010;28:1963-72 CrossRef Medline

23. Boxerman JL, Zhang Z, Safriel Y, et al. Prognostic value of contrast enhancement and FLAIR for survival in newly diagnosed glioblastoma treated with and without bevacizumab: results from ACRIN 6686. Neuro Oncol 2018;20:1400-10 CrossRef Medline

24. Huang RY, Rahman R, Ballman KV, et al. The impact of T2/FLAIR evaluation per RANO criteria on response assessment of recurrent glioblastoma patients treated with bevacizumab. Clin Cancer Res 2016;22:575-81 CrossRef Medline

25. Nowosielski M, Wiestler B, Goebel G, et al. Progression types after antiangiogenic therapy are related to outcome in recurrent glioblastoma. Neurology 2014;82:1684-92 CrossRef Medline

26. Yordanova YN, Moritz-Gasser S, Duffau H. Awake surgery for WHO grade II gliomas within "noneloquent" areas in the left dominant hemisphere: toward a "supratotal" resection: clinical article. J Neurosurg 2011;115:232-39 CrossRef Medline

27. Li YM, Suki D, Hess K, et al. The influence of maximum safe resection of glioblastoma on survival in 1229 patients: can we do better than gross-total resection? J Neurosurg 2016;124:977-88 CrossRef Medline

28. Pessina F, Navarria P, Cozzi L, et al. Maximize surgical resection beyond contrast-enhancing boundaries in newly diagnosed glioblastoma multiforme: is it useful and safe? A single institution retrospective experience. J Neurooncol 2017;135:129-39 CrossRef Medline

29. Beiko J, Suki D, Hess KR, et al. IDH1 mutant malignant astrocytomas are more amenable to surgical resection and have a survival benefit associated with maximal surgical resection. Neuro Oncol 2014;16:81-91 CrossRef Medline

30. Pope WB, Sayre J, Perlina A, et al. MR imaging correlates of survival in patients with high-grade gliomas. AJNR Am J Neuroradiol 2005; 26:2466-74 Medline

31. Lasocki A, Gaillard F, Tacey M, et al. Morphologic patterns of noncontrast-enhancing tumor in glioblastoma correlate with IDH1 mutation status and patient survival. J Clin Neurosci 2018;47: 168-73 CrossRef Medline

32. Baldock AL, Ahn S, Rockne R, et al. Patient-specific metrics of invasiveness reveal significant prognostic benefit of resection in a predictable subset of gliomas. PLoS One 2014;9:e99057 CrossRef Medline

33. Stupp R, Mason WP, van den Bent MJ, et al; European Organisation for Research and Treatment of Cancer Brain Tumor and Radiotherapy Groups, National Cancer Institute of Canada Clinical Trials Group. Radiotherapy plus concomitant and adjuvant temozolo- mide for glioblastoma. $N$ Engl J Med 2005;352:987-96 CrossRef Medline

34. Duma CM, Kim BS, Chen PV, et al. Upfront boost gamma knife "leading-edge" radiosurgery to FLAIR MRI-defined tumor migration pathways in 174 patients with glioblastoma multiforme: a 15year assessment of a novel therapy. J Neurosurg 2016;125(Suppl 1): 40-49 CrossRef Medline

35. Wiki for the VASARI feature set. The National Cancer Institute 2015. https://wiki.cancerimagingarchive.net/display/Public/VASARI+ Research+Project. Accessed November 22, 2018

36. Muccio CF, Tarantino A, Esposito G, et al. Differential diagnosis by unenhanced FLAIR T2-weighted magnetic resonance images between solitary high grade gliomas and cerebral metastases appearing as contrast-enhancing cortico-subcortical lesions. J Neurooncol 2011;103:713-17 CrossRef Medline

37. Stuckey SL, Wijedeera R. Multicentric/multifocal cerebral lesions: can fluid-attenuated inversion recovery aid the differentiation between glioma and metastases? J Med Imaging Radiat Oncol 2008;52: 134-39 CrossRef Medline

38. Tang YM, Ngai S, Stuckey S. The solitary enhancing cerebral lesion: can FLAIR aid the differentiation between glioma and metastasis? AJNR Am J Neuroradiol 2006;27:609-11 Medline

39. Chang PD, Malone HR, Bowden SG, et al. A multiparametric model for mapping cellularity in glioblastoma using radiographically localized biopsies. AJNR Am J Neuroradiol 2017;38:890-98 CrossRef Medline

40. Lasocki A, Gaillard F, Tacey M, et al. Multifocal and multicentric glioblastoma: improved characterisation with FLAIR imaging and prognostic implications. J Clin Neurosci 2016;31:92-98 CrossRef Medline

41. Brandão LA, Shiroishi MS, Law M. Brain tumors: a multimodality approach with diffusion-weighted imaging, diffusion tensor imaging, magnetic resonance spectroscopy, dynamic susceptibility contrast and dynamic contrast-enhanced magnetic resonance imaging. Magn Reson Imaging Clin N Am 2013;21:199-239 CrossRef Medline

42. Guo AC, Cummings TJ, Dash RC, et al. Lymphomas and high-grade astrocytomas: comparison of water diffusibility and histologic characteristics. Radiology 2002;224:177-83 CrossRef Medline

43. Kono K, Inoue $\mathrm{Y}$, Nakayama $\mathrm{K}$, et al. The role of diffusion-weighted imaging in patients with brain tumors. AJNR Am J Neuroradiol 2001;22:1081-88 Medline

44. Tien RD, Felsberg GJ, Friedman H, et al. MR imaging of high-grade cerebral gliomas: value of diffusion-weighted echoplanar pulse sequences. AJR Am J Roentgenol 1994;162:671-77 CrossRef Medline

45. Castillo M, Smith JK, Kwock L, et al. Apparent diffusion coefficients in the evaluation of high-grade cerebral gliomas. AJNR Am J Neuroradiol 2001;22:60-64 Medline

46. Holodny AI, Makeyev S, Beattie BJ, et al. Apparent diffusion coefficient of glial neoplasms: correlation with fluorodeoxyglucose-positron-emission tomography and gadolinium-enhanced MR imaging. AJNR Am J Neuroradiol 2010;31:1042-48 CrossRef Medline

47. Price SJ, Jena R, Burnet NG, et al. Improved delineation of glioma margins and regions of infiltration with the use of diffusion tensor imaging: an image-guided biopsy study. AJNR Am J Neuroradiol 2006;27:1969-74 Medline

48. Stadlbauer A, Ganslandt O, Buslei R, et al. Gliomas: histopathologic evaluation of changes in directionality and magnitude of water diffusion at diffusion-tensor MR imaging. Radiology 2006;240:803-10 CrossRef Medline

49. Ellingson BM, Malkin MG, Rand SD, et al. Validation of functional diffusion maps (fDMs) as a biomarker for human glioma cellularity. J Magn Reson Imaging 2010;31:538-48 CrossRef Medline

50. Zeng Q, Ling C, Shi F, et al. Glioma infiltration sign on high b-value diffusion-weighted imaging in gliomas and its prognostic value. $J$ Magn Reson Imaging 2018 Mar 1. [Epub ahead of print] CrossRef Medline

51. Price SJ, Green HA, Dean AF, et al. Correlation of MR relative cerebral blood volume measurements with cellular density and prolif- 
eration in high-grade gliomas: an image-guided biopsy study. AJNR Am J Neuroradiol 2011;32:501-06 CrossRef Medline

52. Sadeghi N, D'Haene N, Decaestecker C, et al. Apparent diffusion coefficient and cerebral blood volume in brain gliomas: relation to tumor cell density and tumor microvessel density based on stereotactic biopsies. AJNR Am J Neuroradiol 2008;29:476-82 CrossRef Medline

53. Gupta A, Young RJ, Karimi S, et al. Isolated diffusion restriction precedes the development of enhancing tumor in a subset of patients with glioblastoma. AJNR Am J Neuroradiol 2011;32:1301-06 CrossRef Medline

54. Danchaivijitr N, Waldman AD, Tozer DJ, et al. Low-grade gliomas: do changes in rCBV measurements at longitudinal perfusionweighted MR imaging predict malignant transformation? Radiology 2008;247:170-78 CrossRef Medline

55. Stadlbauer A, Gruber S, Nimsky C, et al. Preoperative grading of gliomas by using metabolite quantification with high-spatial-resolution proton MR spectroscopic imaging. Radiology 2006;238: 958-69 CrossRef Medline
56. Castillo M, Smith JK, Kwock L. Correlation of myo-inositol levels and grading of cerebral astrocytomas. AJNR Am J Neuroradiol 2000; 21:1645-49 Medline

57. Nowosielski M, DiFranco MD, Putzer D, et al. An intra-individual comparison of MRI, [18F]-FET and [18F]-FLT PET in patients with high-grade gliomas. PLoS One 2014;9:e95830 CrossRef Medline

58. Lopez WO, Cordeiro JG, Albicker U, et al. Correlation of (18)Ffluoroethyl tyrosine positron-emission tomography uptake values and histomorphological findings by stereotactic serial biopsy in newly diagnosed brain tumors using a refined software tool. Onco Targets Ther 2015;8:3803-15 CrossRef Medline

59. Artzi M, Liberman G, Blumenthal DT, et al. Differentiation between vasogenic edema and infiltrative tumor in patients with high-grade gliomas using texture patch-based analysis. J Magn Reson Imaging 2018 Jan 3. [Epub ahead of print] CrossRef Medline

60. Hu LS, Ning S, Eschbacher JM, et al. Multi-parametric MRI and texture analysis to visualize spatial histologic heterogeneity and tumor extent in glioblastoma. PLoS One 2015;10:e141506 CrossRef Medline 